\title{
Therapeutic Potential of Inhibitors of Endocannabinoid Degradation for the Treatment of Stress-Related Hyperalgesia in an Animal Model of Chronic Pain
}

\author{
Ermelinda Lomazzo', Laura Bindila', Floor Remmers', Raissa Lerner', Claudia Schwitter', Ulrich Hoheisel ${ }^{2}$ \\ and Beat Lutz*, I \\ Institute of Physiological Chemistry, University Medical Center of the Johannes Gutenberg University, Mainz, Germany; ${ }^{2}$ Department of \\ Neurophysiology, CBTM, Medical Faculty Mannheim, Heidelberg University, Germany
}

\begin{abstract}
The occurrence of chronic stress, depression, and anxiety can increase nociception in humans and may facilitate the transition from localized to chronic widespread pain. The mechanisms underlying chronic widespread pain are still unknown, hindering the development of effective pharmacological therapies. Here, we exposed C57BL/6J mice to chronic unpredictable stress (CUS) to investigate how persistent stress affects nociception. Next, mice were treated with multiple intramuscular nerve growth factor (NGF) injections, which induced chronic widespread nociception. Thus, combination of CUS and NGF served as a model where psychophysiological impairment coexists with long-lasting hyperalgesia. We found that CUS increased anxiety- and depression-like behavior and enhanced basal nociception in mice. When co-applied with repeated NGF injections, CUS elicited a sustained long-lasting widespread hyperalgesia. In order to evaluate a potential therapeutic strategy for the treatment of chronic pain associated with stress, we hypothesized that the endocannabinoid system (ECS) may represent a target signaling system. We found that URB597, an inhibitor of the anandamidedegrading enzyme fatty acid amide hydrolase (FAAH), and JZLI84, an inhibitor of the 2-arachidonoyl glycerol-degrading enzyme monoacylglycerol lipase (MAGL), increased eCB levels in the brain and periphery and were both effective in reducing CUS-induced anxiety measured by the light-dark test and CUS-induced thermal hyperalgesia. Remarkably, the long-lasting widespread hyperalgesia induced by combining CUS and NGF was effectively reduced by URB597, but not by JZLI84. Simultaneous inhibition of FAAH and MAGL did not improve the overall therapeutic response. Therefore, our findings indicate that enhancement of anandamide signaling with URB597 is a promising pharmacological approach for the alleviation of chronic widespread nociception in stress-exposed mice, and thus, it could represent a potential treatment strategy for chronic pain associated with neuropsychiatric disorders in humans. Neuropsychopharmacology (20I5) 40,488-50I; doi:I0.I038/npp.2014.198; published online 3 September 20I4
\end{abstract}

\section{INTRODUCTION}

The occurrence of chronic widespread muscular pain is a leading cause of disability and a major source of health-care costs. High incidence of chronic myofascial pain has been reported in patients suffering from depression and anxiety (Bailey et al, 2010). This suggests that psychophysiological factors interacting with the pain-modulating system may ultimately lead to the intensification of peripherally perceived pain (Sharif-Naeini and Basbaum, 2011; Saab, 2012). As neurobiological mechanisms underlying widespread myofascial pain associated with emotional dysregulation are poorly understood, establishing appropriate animal models and, consequently, designing effective

* Correspondence: Professor B Lutz, Institute of Physiological Chemistry, University Medical Center of the Johannes Gutenberg University, Duesbergweg 6, Mainz 55128, Germany, Tel: +49 6131 39-25912, Fax: +49 6131 39-23536, E-mail: blutz@uni-mainz.de

Received 2I May 20 I; revised 21 July 20 14; accepted I August 20 14; accepted article preview online 6 August 2014 pharmacological therapies for patients suffering from chronic pain associated with neurological diseases, have been challenging so far.

The endocannabinoid system (ECS) consists of two major endogenous ligands, anandamide (AEA) and 2-arachidonoyl glycerol (2-AG), which bind to the CB1 receptor, located in both central and peripheral nervous system, and the $\mathrm{CB} 2$ receptor, mainly expressed in the periphery. The ECS represents a key modulator in neuropsychiatric disorders (Moreira et al, 2008) and pain states (Kinsey et al, 2010; Maione et al, 2013). Inhibitors of eCB degradation have anxiolytic properties and are effective for the treatment of multiple types of pain. However, the mechanisms by which eCB signaling enhancing drugs modulate chronic pain associated with neurological diseases have remained largely unknown (Hill et al, 2005; Reich et al, 2009). Chronic unpredictable stress (CUS) is a common procedure to induce anxiety- and depression-like behaviors in rodents (Mineur et al, 2006). CUS is known to affect pain sensitivity (Shi et al, 2010) and to promote impairment of eCB signaling in the brain (Wang et al, 2010). 
The present study aims at (i) establishing a valid mouse model of chronic widespread pain associated with emotional disturbance and at (ii) investigating whether pharmacological enhancement of eCB signaling represents a therapeutic strategy for the alleviation of this type of pain. As a model of myofascial widespread pain, we used repeated intramuscular injections of nerve growth factor (NGF), which is known to be associated with fascia and muscle pain (Hoheisel et al, 2005, 2007; Hayashi et al, 2011; Deising et al, 2012) and to induce long-lasting hyperalgesia in animals (Hoheisel et al, 2007; Mills et al, 2013) and humans (Herren-Gerber et al, 2011; Deising et al, 2012; Hayashi et al, 2013). Antibodies against NGF are currently under investigation for pain treatment in humans (Cattaneo, 2010; Pfizer, 2012). In addition, it has recently been shown that intramuscular NGF injections in rats cause a transient hyperalgesia followed by a latent sensitization of dorsal horn neurons (Hoheisel et al, 2013). A second NGF injection given in that state causes a strong spinal sensitization accompanied by a long-lasting hyperalgesia, suggesting that repeated intramuscular administration of NGF represents an adequate model of chronic pain in rodents. In the present study, the rationale for using multiple NGF injections is to induce a long-lasting hyperalgesia in mice. The combination of CUS and NGF is necessary to establish an animal model where the stress-induced emotional imbalance coexists with the NGF-induced chronic nociception, to finally mimic in mice the condition of patients suffering from chronic pain as a consequence of a neuropsychiatric disease. Therefore, we aim at investigating first, whether basal nociception and emotional state are affected by persistent stress (CUS alone), and second, how the NGF-induced hyperalgesia is affected in mice exposed to CUS. Finally, we put forward the notion that pharmacological interventions aimed at increasing eCB levels in central and peripheral nervous system, may result in relief of stressmodulated chronic pain. We compared the therapeutic effects of chronic administration of URB597, JZL184, and a combination of both drugs to establish which eCB (AEA or 2-AG) has a predominant modulating role and which pharmacological approach is more effective to alleviate the emotional imbalance and hyperalgesia in the CUS/NGF mouse model.

\section{MATERIALS AND METHODS}

\section{Animals}

Male C57BL/6J mice (6-weeks old) were used for these studies. Mice were housed in a temperature- and humiditycontrolled room with food and water at libitum and light phase from 0700 to 1900 hours. Tests were carried out during the light phase. At the end of the experimental procedures, mice were anesthetized with isoflurane and euthanized by decapitation. Experimental procedures were approved by the German State Rhineland-Palatinate (AZ. Nr. 23 177-07/G12-1-044).

\section{Drug Treatments}

URB597 (3'-(aminocarbonyl) [1, 1'-biphenyl]-3-yl)-cyclohexylcarbamate and JZL184 (4-nitrophenyl-4-[bis(1,3-benzo- dioxol-5-yl)(hydroxy)methyl]piperidine-1-carboxylate) were purchased from Cayman Chemical, dissolved in vehicle consisting of DMSO-cremophor-saline $(1: 1: 18)$ and delivered by i.p. injection in a volume of $10 \mathrm{ml} / \mathrm{kg}$ body weight. URB597 and JZL184 were administered individually or in combination (combo treatment) at $1 \mathrm{mg} / \mathrm{kg} /$ day and $8 \mathrm{mg} / \mathrm{kg} /$ day, respectively. Previous reports have shown that URB597 and JZL184 used at these doses fully block enzyme activity, increase eCB levels, are devoid of side effects, and elicit behavioral responses in rodents (Moreira et al, 2008, for URB597; Kinsey et al, 2013, for JZL184). Vehicle-treated animals received an equivalent i.p. injection of vehicle without drug. Vehicle and drugs were prepared fresh daily and administered $1 \frac{1 / 2}{h}$ before tests. Human recombinant $\beta$-NGF was purchased from Calbiochem and dissolved in sterile phosphate-buffered saline (PBS). $0.75 \mu \mathrm{g}$ of NGF in $30 \mu \mathrm{l}$ volume was injected into the left gastrocnemius-soleus (GS) muscle. Equivalent injections of PBS without NGF were administered contralaterally and used as control.

\section{CUS}

The CUS procedure was modified from previous reports (Mineur et al, 2006; Wang et al, 2010) and is described in Table 1. Exposure to chronic stress lasted for the entire duration of the experimental procedure (Figure 1). To avoid animal adaptation, two to three stressors were applied daily in a random manner.

\section{Behavioral Assays}

Elevated plus-maze (EPM) and light-dark test (LDT) are well-established methods to measure anxiety-like behavior in rodents and were used here as described before (Moreira et al, 2008). A video surveillance system recorded animal behavior for $5 \mathrm{~min}$ in both tests. The time spent in the open arms of EPM and in the lit compartment of LDT is expressed as percentage of total test time $(300 \mathrm{~s})$. The

Table I Description of the Stressors Applied (CUS Procedure)

\begin{tabular}{|c|c|}
\hline \multirow[t]{3}{*}{ Space stressors } & Isolation (one animal per cage; 2-4h or overnight) \\
\hline & Reduction of space in home cage ( 6 animals per cage) \\
\hline & Restraint stress: restrain device made of Plexiglas $(\mathrm{I}-2 \mathrm{~h})$ \\
\hline \multirow{4}{*}{$\begin{array}{l}\text { Cage alteration } \\
\text { stressors }\end{array}$} & Empty cage (no sawdust; $4 \mathrm{~h}$ ) \\
\hline & Sawdust substituted with $2 \mathrm{~cm}$ water $(2 \mathrm{~h})$ \\
\hline & Wet bedding $(4 h)$ \\
\hline & Dirty cage $(4 \mathrm{~h})$ \\
\hline \multirow[t]{2}{*}{ Light-dark stressors } & Overnight light ( $12 \mathrm{~h})$ \\
\hline & Inverted light-dark cycle \\
\hline $\begin{array}{l}\text { Food/water } \\
\text { stressors }\end{array}$ & $\begin{array}{l}\text { Deprivation of food, water, or both (during dark } \\
\text { or light phase; } 3-4 \mathrm{~h} \text { ) }\end{array}$ \\
\hline \multirow[t]{5}{*}{ Other stressors } & Cage tilt ( $\sim 30^{\circ}$ inclination for $2-3 \mathrm{~h}$ ) \\
\hline & $\begin{array}{l}\text { Shaking (cage on lab shaker generating } 220 \\
\text { shakings per minute; } 1-2 \mathrm{~h} \text { ) }\end{array}$ \\
\hline & Intermittent water puff ( $5 \mathrm{~min}$ ) \\
\hline & White noise ( $100 \mathrm{~dB} ; 5-10 \mathrm{~min})$ \\
\hline & Exposure to older or aggressive intruder (2-4h) \\
\hline
\end{tabular}




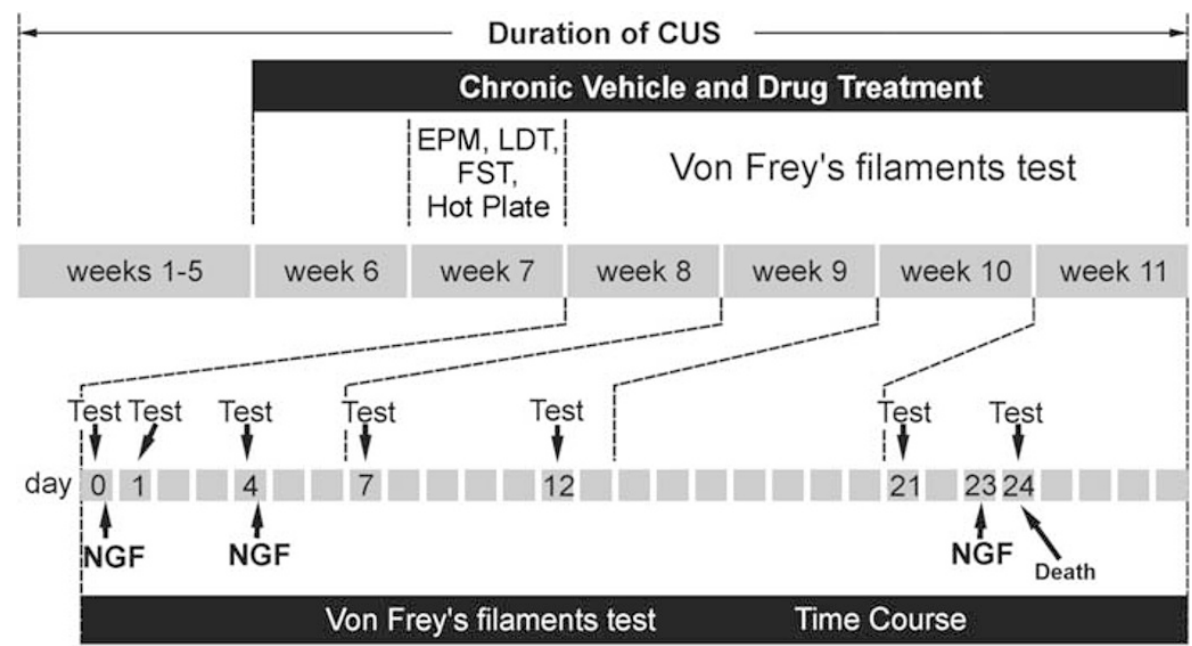

Figure I Scheme of experimental procedure. Two groups of mice were exposed to CUS or kept in the home cage as controls for 5 weeks. Then, mice were daily injected with vehicle and drugs, respectively, for I week (week 6). In week 7, mice were tested for anxiety-and depression-like behavior, and pain perception in the hot plate test. The Von Frey's filaments test was carried out from weeks 8 to I I at the indicated time points (bottom). NGF was injected three times to induce long-lasting hyperalgesia. NGF administration was carried out on days 0 and 4, immediately after the Von Frey's filaments test was performed on these days and finally on day 23. On day 24, the last Von Frey's filaments test was carried out and afterwards, tissues were isolated for analysis of eCB levels. Exposure to CUS was constantly applied for the entire duration of the experimental procedure. CUS, chronic unpredictable stress; EPM, elevated plus maze; FST, forced swim test; LDT, light-dark test; NGF, nerve growth factor.

frequency in EPM is expressed as percentage of total arm entries, whereas in LDT, it refers to the number of times mice enter the bright area with all four paws. The forced swim test (FST, Porsolt's test) is a common method to measure depression-like responses in rodents. Mice were forced to swim in a 5-1 glass beaker containing water up to $15 \mathrm{~cm}$ of height at $25 \pm 1{ }^{\circ} \mathrm{C}$, and behavior was videotaped for 5 min (Häring et al, 2013). Immobility time is expressed as percentage of the total test time (300 s).

\section{Pain-Related Behaviors}

Thermal hyperalgesia was measured with the hot plate test (Ugo Basile, Italy). Mice were placed on a surface heated at $48{ }^{\circ} \mathrm{C}$ and the latency to the first reaction to the heat (paw lifting, paw licking or jumping) was scored. To measure mechanical hyperalgesia, Von Frey's filaments were used (Ugo Basile, Italy). Mice were placed in a plastic chamber with a perforated metal grid floor. The plantar surface of right and left hind paws was stimulated five times each with nylon filaments $(0.16-4.0 \mathrm{~g})$, starting with the $0.6 \mathrm{~g}$ filament and using the 'up-down' method (Chaplan et al, 1994) to establish the sensory threshold for each paw. Paw withdrawal in response to three or more stimulations was recorded as a positive response. As no difference between NGF- and PBS-injected sides was observed, the responses from both sides were averaged and expressed as paw withdrawal threshold.

\section{Tissue Collection and eCB Extraction}

Mice were anesthetized with isoflurane and euthanized by decapitation. Brains and GS muscles were quickly isolated, dissected, and frozen at $-80^{\circ} \mathrm{C}$ until use. Trunk blood was collected in EDTA-coated tubes and spun at $2000 \mathrm{~g}$ at $4{ }^{\circ} \mathrm{C}$ for $12 \mathrm{~min}$. Serum was immediately collected and stored at $-80^{\circ} \mathrm{C}$ until use. Tissues were transferred to extraction tubes containing steel beads. A spiking solution of deuterated eCBs in acetonitrile was mixed with $0.1 \mathrm{M}$ formic acid (for brain tissues) or $50 \mathrm{mM}$ Tris buffer (for GS muscles) as homogenization buffer and rapidly pipetted to the extraction tubes using an automated pipetting procedure (ThermoScientific). Ethylacetate/hexane $(9: 1)$ for eCBs extraction was then added. Tissues were homogenized with a tissue lyser (Qiagen, $30 \mathrm{~Hz}$ for $1 \mathrm{~min}$ ), centrifuged at $5000 \mathrm{~g}$ for $15 \mathrm{~min}$ at $4{ }^{\circ} \mathrm{C}$ and kept for $30 \mathrm{~min}$ at $-20^{\circ} \mathrm{C}$ to freeze the aqueous phase. The upper organic phase was recovered in microtiter plates, evaporated, and the extracts reconstituted in $50 \mu \mathrm{l}$ water/acetonitrile $(1: 1)$ using an automated pipetter. The extraction of eCBs from serum $(50 \mu \mathrm{l})$ followed the same procedure, except that homogenization was replaced by vortexing steps. Throughout the extraction procedure, tubes/plates were invariably kept at $4{ }^{\circ} \mathrm{C}$ to prevent alterations of eCB levels originating from enzymatic or chemical degradation and/or ex-vivo synthesis of eCBs. The amounts of internal standards and concentration range of calibration curves were tailored to the tissue type.

\section{Liquid Chromatography (LC)/Multiple Reaction Monitoring (MRM)}

$20 \mu$ of the solution of extracted eCBs were injected and separated on a Phenomenex Luna $2.5 \mu \mathrm{m}$ C18(2)-HST column, $100 \times 2 \mathrm{~mm}^{2}$, combined with a pre-column (C18, $4 \times 2 \mathrm{~mm}^{2}$; Phenomenex, Aschaffenburg, Germany), by increasing acetonitrile containing $0.1 \%$ formic acid over 2 min from 55 to $90 \%$, and maintaining it at $90 \%$ for $5.5 \mathrm{~min}$. The separated eCBs were flow-through analyzed using MRM on a 5500 QTrap triple-quadrupole linear ion trap mass spectrometer equipped with a Turbo $\mathrm{V}$ Ion Source (AB SCIEX, Darmstadt, Germany). Positive and negative ions were simultaneously analyzed using the 
'positive-negative-switching' mode. The following MRM transitions were monitored for quantification of eCBs: AEA, $m / z 348.3$ to $m / z$ 62.3; AEA-d4, $m / z 352.3$ to $m / z 62.1$; 2-AG, $m / z 379.1$ to $m / z 287.2 ; 2-A G-d 5, m / z 384.1$ to $\mathrm{m} / z$ 287.2; PEA, $m / z 300.2$ to $\mathrm{m} / z$ 62.1; PEA-d4, $\mathrm{m} / z 304.2$ to $\mathrm{m} / \mathrm{z}$ 62.1. Calibration solutions were prepared using commercially available standards of high purity, spiked with a mixure of deuterated eCBs and run in triplicate. Quantification of eCBs was carried out using Analyst 1.6.1 software. The eCB concentrations were normalized to protein content (for tissues) measured by BCA and to serum volume.

\section{Data Analysis}

Data were analyzed with the Statistical Package for Social Science (SPSS version 19.0). Statistical analyses of the difference between group means were carried out by twoway analysis of variance (ANOVA) for 'treatment' (vehicle $v s$ drugs) and 'stress' (control vs CUS). In addition to the two-way ANOVA for each day of testing, the results of the Von Frey's filaments test were further analyzed by threeway repeated measurements ANOVA for 'day' (referred to the day when the test was performed, repeated factor), 'treatment' (vehicle vs drugs), and 'stress' (control vs CUS). One-way ANOVA to identify differences in response between specific time points in each individual group (control and CUS mice with vehicle and drug treatments) was also used. ANOVA was followed by planned comparison between specific groups using Bonferroni's multiple comparison test. Data are presented as mean \pm SEM and considered significant at a $p$-value $<0.05$.

\section{RESULTS}

\section{Experimental Design}

C57BL/6J mice were exposed to the CUS procedure (Table 1 and Figure 1) and received daily administrations of vehicle or drugs starting from week 6. Exposure to CUS lasted for the entire experimental procedure. In week 7, EPM, LDT, FST, and hot plate tests were carried out, $1 \frac{1 / 2}{2}$ after vehicle or drug administration. From weeks 8 to 11 , mice were evaluated in the Von Frey's filaments test, which was carried out at the indicated time points (days), $1 \frac{1 / 2}{\mathrm{~h}}$ after vehicle or drug injections (Figure 1). To induce long-lasting hyperalgesia, mice received three NGF injections into the left GS muscle, the first one on day 0 (Figure 1), the second one on day 4, both administered immediately after the Von Frey's filaments test carried out on these days, and the third one on day 23. Repetitive applications of Von Frey's filaments do not induce sensitization in rodents and therefore, the nociceptive response is not affected over time (Sluka et al, 2001). On day 24, mice were treated, tested again, and immediately euthanized. Mice exposed to CUS showed a significant decrease in body weight as compared with controls $(p<0.01$, Student's $t$-test, data not shown), in agreement with previous reports (Wang et al, 2010).

\section{Anxiety- and Depression-Like Behaviors}

Anxiety-like behavior was evaluated in control and CUS mice by EPM and LDT (Figure 2a-d; two-way ANOVA in
Table 2). In the EPM, both duration $(p<0.001)$ and frequency $(p<0.001)$ in the open arms were significantly reduced in CUS mice, indicating an increase in anxiety-like behavior in these animals compared with controls (Figure 2a and b). Upon treatment with URB597, stressinduced anxiety-like behavior was partially recovered, as shown by the increased duration and frequency of CUS mice in the open arms of EPM. In contrast, JZL184 and combo (URB597 + JZL184) treatments did not relieve the stress-induced anxiety-like behavior in the EPM test, indicating that the 'treatment $\times$ stress' interaction reported in Table $2\left(\mathrm{~F}_{(3,68)}=4.014, p=0.01\right.$, referring to Figure $\left.2 \mathrm{~b}\right)$ refers to the anxiolytic properties of URB597 in CUS mice. Surprisingly, control animals that received JZL184 or combo treatment showed a reduction in duration and frequency in the open arms of the EPM as compared with vehicle-treated controls, suggesting an anxiogenic effect, which did not occur with URB597 treatment alone (Figure $2 \mathrm{a}$ and $\mathrm{b}$ ). CUS mice also showed reduced time $(p<0.001)$ and frequency $(p<0.01)$ in the lit compartment of the LDT (Figure 2c and d). Both URB597 and JZL184 administration prolonged the time that CUS mice spent in the lit compartment as compared with the vehicle-treated CUS animals $(p<0.01$ for URB597; $p<0.05$ for JZL184, Figure 2c). Frequency of entries of CUS mice into the lit compartment was augmented by all three treatments $(p<0.01$ for URB597; $p<0.01$ for JZL184; $p<0.001$ for combo). Drugs had no effect in control animals in the LDT. Next, we investigated the effects of CUS on depression-like responses in mice by using FST (Figure 2e and f; two-way ANOVA in Table 2). CUS-exposed mice showed increased immobility time $(p<0.001)$ and decreased latency to the first immobility $(p<0.001)$ as compared with controls, indicating impaired motivational drive (Figure $2 \mathrm{e}$ and $\mathrm{f}$ ). Drug treatments failed to recover the depression-like behavior in CUS mice (Figure 2e and $\mathrm{f}$ ). However, in control animals, JZL184 and combo treatments prolonged the immobility time and reduced the latency to the first immobility, suggesting a depression-like behavior. URB597 treatment had no significant effects in control mice (Figure 2e and $\mathrm{f}$ ). To investigate whether the anxiety- and depression-like behaviors induced by JZL184 and combo in control mice resulted from drug-induced cannabimimetic effects, as reported for high doses of JZL184 and combined fatty acid amide hydrolase (FAAH)/monoacylglycerol lipase (MAGL) inhibitors (Long et al, 2009b; Wise et al, 2012), we tested mice in the tetrad behavioral paradigm. We found that temperature, catalepsy (bar test), and locomotion (EPM and open field tests) were not changed in drug-treated mice as compared with vehicle-treated animals (data not shown).

\section{Thermal and Mechanical Hyperalgesia}

CUS mice tested in the hot-plate test (Figure 2g; two-way ANOVA in Table 2) showed a shorter latency to react to the heat compared with controls $(p<0.01$, Figure $2 \mathrm{~g}$ ), indicating that CUS induced thermal hyperalgesia. Drug treatments prolonged the reaction latency in CUS mice ('treatment $\times$ stress' interaction, $\mathrm{F}_{(3,68)}=2.969, \quad p<0.05$, Table 2), although statistical significance was achieved only with JZL184 (CUS-vehicle vs CUS-JZL184, $p<0.01$ ), whereas a tendency was found in combo-treated CUS mice as 

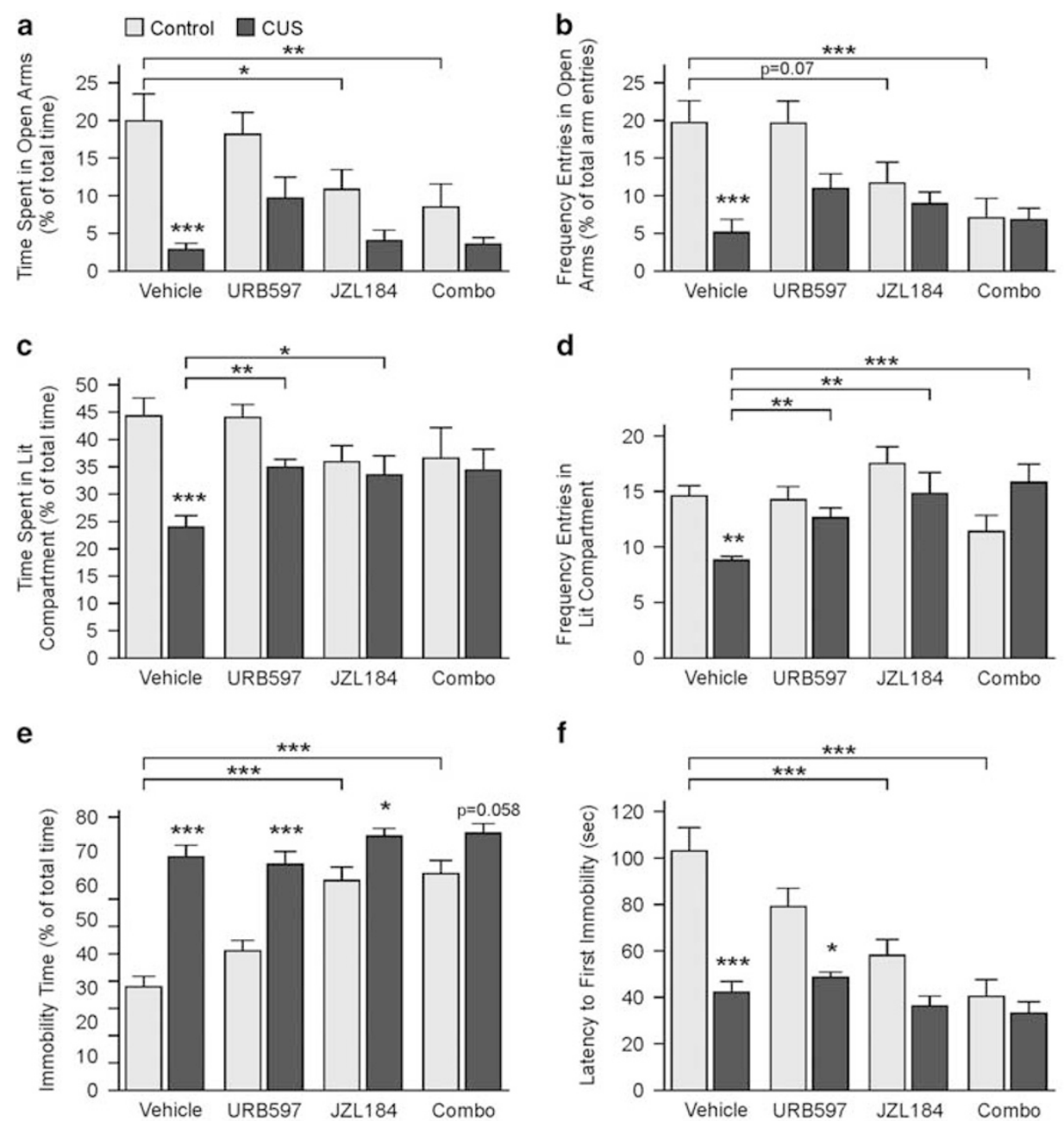

f

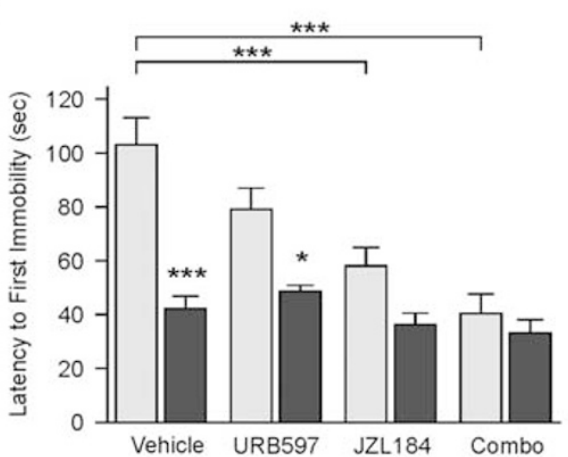

g
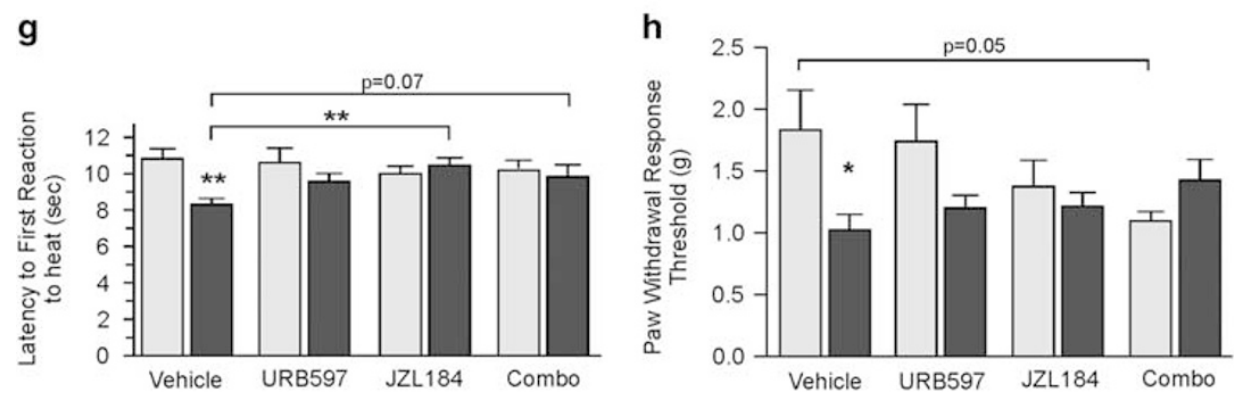

Figure 2 Analysis of anxiety- and depression-like behavior, and hyperalgesia. (a and b) Elevated plus maze (EPM): vehicle-treated CUS mice showed reduced duration (a) and frequency (b) in the open arms of the EPM indicating an increase in anxiety-like behavior as compared with controls. URB597 administration increased duration (a) and frequency (b) of CUS mice in the open arms, indicating an anxiolytic effect. JZLI 84 and combo (URB597 + JZL I84) treatments decreased duration (a) and frequency (b) of control mice in the open arms of EPM, and had no significant effects in CUS mice. (c and d) Light-dark test LDT: vehicle-treated CUS mice showed reduced time (c) and frequency (d) in the lit compartment of the LDT as compared with controls. URB597, IZLI84, and combo administration increased the time (c) and the frequency (d) of CUS mice in the lit compartment, suggesting reduced anxietylike behavior. (e and f) Forced swim test (FST): vehicle-treated CUS mice spent more time immobile (e) and showed shortened latency to the first immobility in the forced swim test $(f)$ as compared with controls, suggesting increased depression-like behavior. In control mice, JZLI84 and combo treatments prolonged immobility time and shortened latency to the first immobility, but had no effect in CUS mice (e and f). URB597 had no effect in both animal groups ( $\mathrm{e}$ and $\mathrm{f}$. Time spent in open arms of EPM is expressed as percentage of total test time (300 s) and frequency as percentage of total arm entries. Time spent in the lit compartment of LDT and immobility time in FST are expressed as percentage of total test time (300 s). Frequency in LDT refers to the total number of entries in the lit compartment. (g) Hot plate test: CUS mice treated with vehicle showed a shorter latency of reaction to the heat source as compared with the vehicle-treated control group (g). URB597, IZLI84, and combo treatment prolonged the latency of reaction in CUS mice, indicating an anti-nociceptive effect (g). (h) Von Frey's filaments test, day 0: CUS mice treated with vehicle showed decreased pain threshold and, thus, increased mechanical hyperalgesia as compared with the vehicle-treated control group. Drug treatments did not reverse the CUS-induced mechanical hyperalgesia in mice $(\mathrm{h})$. Data are expressed as stimulus intensity in gram $(\mathrm{g})$ that elicited the response to determine paw withdrawal threshold (h). Statistical differences between control and CUS mice are indicated above the CUS bar; differences between specific groups are shown on the indicated lines. ${ }^{*} p<0.05$, ${ }^{*} p<0.01$, ${ }^{*} * * p<0.00$ I, Bonferroni's multiple comparison tests after significant two-way ANOVA; $n=8-10$ animals in each group. Additional statistical analyses are reported in Table 2. 
Table 2 Statistical Data Analyses (referred to in Figure 2)

Two-way ANOVA

\begin{tabular}{|c|c|c|}
\hline Test & Effect & Significance \\
\hline \multirow[t]{3}{*}{ EPM-time (Figure 2a) } & Stress & $F_{(1,68)}=29.09 I, p<0.001$ \\
\hline & Treatment & $F_{(3,68)}=4.196, p<0.01$ \\
\hline & Treatment $\times$ stress & $F_{(3,68)}=2.560, p=0.06$ \\
\hline \multirow[t]{3}{*}{ EPM frequency (Figure 2b) } & Stress & $F_{(1,68)}=|5.903, p<0.00|$ \\
\hline & Treatment & $F_{(3,68)}=4.4 I I, p<0.01$ \\
\hline & Treatment $\times$ stress & $F_{(3,68)}=4.014, p=0.01$ \\
\hline \multirow[t]{2}{*}{ LDT-time (Figure 2c) } & Stress & $F_{(1,68)}=12.002, p=0.001$ \\
\hline & Treatment $\times$ stress & $F_{(3,68)}=3.180, p<0.05$ \\
\hline \multirow[t]{2}{*}{ LDT frequency (Figure 2d) } & Treatment & $F_{(3,68)}=3.881, p=0.01$ \\
\hline & Treatment $\times$ stress & $F_{(3,68)}=5.277, p<0.01$ \\
\hline \multirow[t]{3}{*}{ FST immobility (Figure 2e) } & Stress & $F_{(1,68)}=86.969, p<0.001$ \\
\hline & Treatment & $F_{(3,68)}=|8.945, p<0.00|$ \\
\hline & Treatment $\times$ stress & $F_{(3,68)}=7.112, p<0.001$ \\
\hline \multirow[t]{3}{*}{ FST-latency (Figure 2f) } & Stress & $F_{(1,67)}=41.242, p<0.001$ \\
\hline & Treatment & $F_{(3,67)}=|2.26|, p<0.00 \mid$ \\
\hline & Treatment $\times$ stress & $F_{(3,67)}=6.141, p=0.001$ \\
\hline \multirow[t]{2}{*}{ Hot plate (Figure 2g) } & Stress & $F_{(1,68)}=5.248, p<0.05$ \\
\hline & Treatment $\times$ stress & $F_{(3,68)}=2.969, p<0.05$ \\
\hline \multirow[t]{2}{*}{ Von Frey (Figure 2h) } & Stress & $F_{(1,68)}=4.552, p<0.05$ \\
\hline & Treatment $\times$ stress & $F_{(3,68)}=3.326, p<0.05$ \\
\hline
\end{tabular}

Abbreviations: EPM, elevated plus maze; FST, forced swim test; LDT, light-dark test; Von Frey, referred to the Von Frey's filaments test carried out on day 0 and reported in Figures $2 \mathrm{~h}$ and 3.

Two-way ANOVA of results shown in Figure 2. The effects of 'stress', 'treatment', and the 'treatment $x$ stress' interaction for each test ( $F$ and $p$ values) are reported, for simplicity, only when a statistical significance or a tendency to significance was found. Results were further analyzed by Bonferroni's post-hoc test to identify differences between group means. Statistical results from post-hoc analysis are shown as asterisks in Figure 2.

compared with vehicle-treated animals (CUS-vehicle $v s$ CUS-combo, $p=0.07$ ). The tests with Von Frey's filaments showed that mice exposed to CUS developed a mechanical hyperalgesia indicating an increased pain perception compared with control animals $(p<0.05$, Figure $2 \mathrm{~h})$. In contrast to the thermal hyperalgesia (Figure 2g), drug treatment did not reduce the stress-induced mechanical hyperalgesia in mice. Data presented in Figure $2 \mathrm{~h}$ corresponds to the Von Frey's filaments test measurement carried out on day 0 of the time course shown in Figure 3. These data are reported here (figure $2 \mathrm{~h}$ ) as bar graphs to better visualize the effect of CUS exposure alone (no NGF administration has been performed yet) on mechanical hyperalgesia in mice.

\section{Chronic Widespread Pain Model}

Mechanical hyperalgesia was measured with the Von Frey's filaments test (Figure 3 and Supplementary Figure 1). Three-way repeated ANOVA for 'day' (repeated factor), 'treatment', and 'stress' disclosed statistically significant interactions among these factors (Table 3). At each specific time point (day), the 'treatment $\times$ stress' interaction also revealed statistically significant differences in response in the eight animal groups analyzed (control and CUS mice with vehicle, URB597, JZL184, and combo treatment; twoway ANOVA in Table 3). Mechanical hyperalgesia was measured either under basal conditions (before NGF injections) or after NGF injections into the left GS muscle (injections on day 0,4 , and 23, Figure 1). No difference in response between NGF- and PBS-injected sides was found (data not shown), suggesting that hyperalgesia spreads to the contralateral side. Similar data have been reported in other animal models of chronic muscle pain (Sluka et al, 2001; Chang et al, 2010). At the pre-NGF time point (day 0, Figure 3a), CUS animals showed enhanced nociception as compared with controls $(p<0.05)$. Injection of NGF induced strong hyperalgesia in mice, which, however, was statistically significant in control animals only (day $0 v s 1$, controls, $p<0.01$, one way-ANOVA). Indeed, NGF-induced hyperalgesia was generally less manifest in CUS mice compared with controls, probably because the basal nociception in these mice was elevated even before NGF administration. On day 4, hyperalgesia was still present in CUS mice (day $0 v s 4, p=0.06$, one way-ANOVA), whereas in control mice, the pain threshold was restored to the basal level (day $0 v s 4$, not significant). The second NGF injection induced a further prolonged nociception in mice (day $0 \mathrm{vs} 7$, control, $p<0.001$; CUS, $p<0.05$, one-way ANOVA), since on day 7 , hyperalgesia was still significantly elevated in both animal groups, indicating that double NGF administration induces long-lasting hyperalgesia. On days 12 and 21 , control and CUS mice showed again a difference in pain threshold, similar to that measured at the basal level (day 0 , pre-NGF), suggesting that at this time point the effect of NGF has been cleared off. To restore the hyperalgesia before collecting tissues, mice received a last NGF injection on day 23 and pain threshold was measured before killing one day later (day 24). Hyperalgesia was again observed in control mice (day 0 vs $24, p<0.01$, one way-ANOVA), whereas in the CUS mice, pain threshold remained persistently low also at this time point. In control animals, URB597, JZL184, and combo administration (Figure $3 \mathrm{~b}, \mathrm{~d}$ and $\mathrm{f}$, respectively) did not evoke relief from the NGF-induced hyperalgesia. On the other hand, in CUS mice, URB597 treatment promoted a strong overall relief in nociception, particularly on the days following NGF injections (day $1, p<0.01$; day $7, p<0.001$; day $24, p<0.001$, Figure $3 c$ and Supplementary Figure 1a), when pain sensitivity was increased. Moreover, in CUS mice, URB597 reversed both the early (day 1) and the prolonged hyperalgesia (day 7) induced by the two NGF administrations but had no effect on the basal stressinduced hyperalgesia (day 0). This suggests that FAAH inhibition reverses hyperalgesia in CUS mice only when stress is combined with an additional nociceptive stimulus (NGF). The analgesic effects of JZL184 and combo administration in CUS mice were less marked as compared with URB597, as a slight relief in hyperalgesia was observed only on day $24(p<0.05)$ of JZL184-treated (Figure $3 \mathrm{e})$ and on day $7(p<0.05)$ of combo-treated CUS mice (Figure $3 \mathrm{e}$ and $\mathrm{g}$ and Supplementary Figure 1). Data presented in Supplementary Figure 1 correspond to those in Figure 3 with a different arrangement to improve visibility of the effects of drugs in each animal group. 

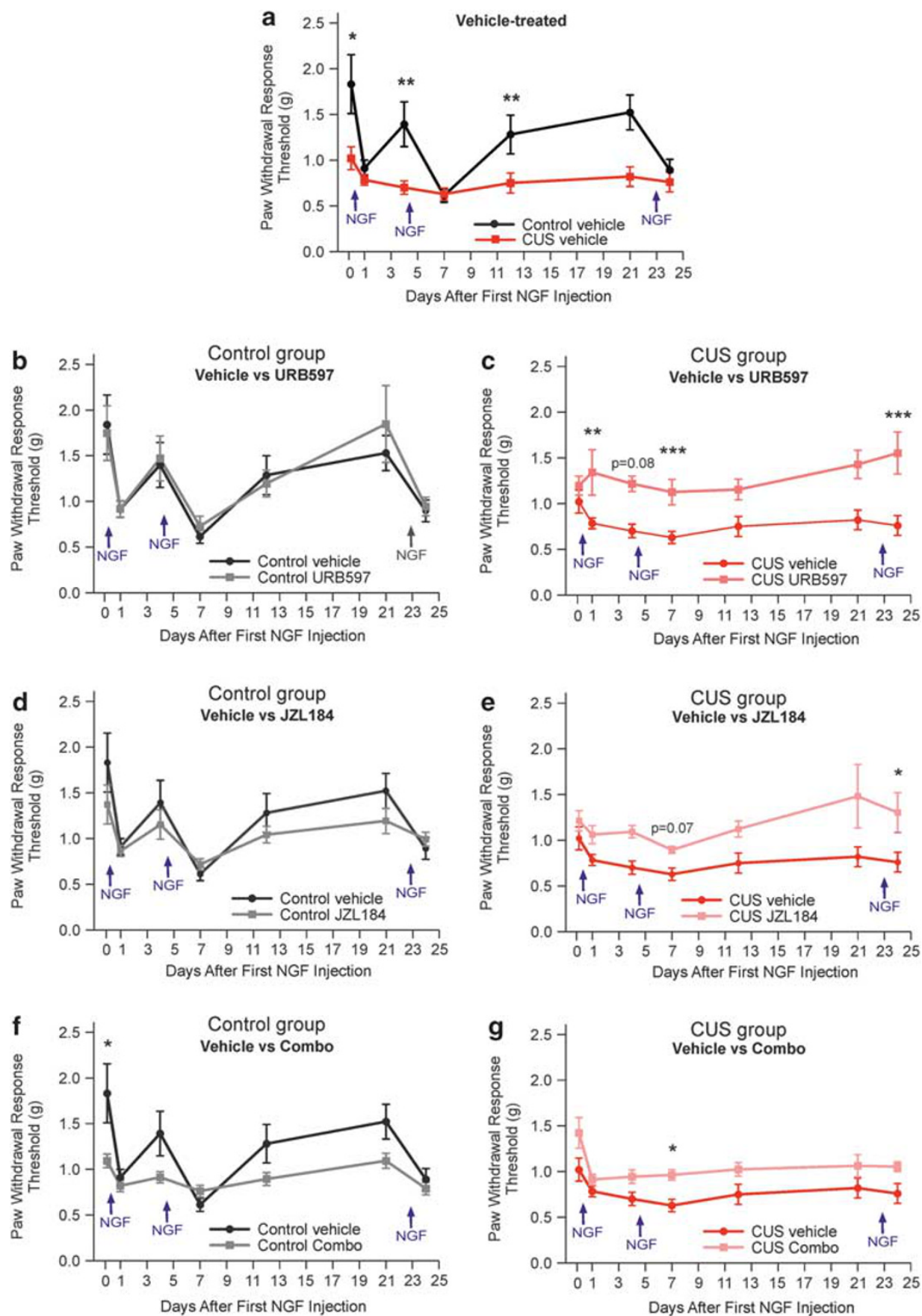

Figure 3 Analysis of pain threshold as measured with the Von Frey's filaments test. For statistical analyses, all eight animal groups (control and CUS mice with vehicle and drug treatments) were compared in one analysis. However, responses from vehicle-treated (a), URB597-treated (b and c), JZLI 84-treated ( $\mathrm{d}$ and $\mathrm{e}$ ), and combo ( $\mathrm{f}$ and $\mathrm{g}$ )-treated animals are presented separately to improve readability of the data. Mice received NGF administration on days 0 and 4, immediately after the Von Frey's filaments test performed on these days and finally on day 23. At the pre-NGF time point (day 0), vehicle-treated CUS mice showed decreased pain threshold, indicating increased nociception compared with controls (a). Differences in pain threshold between vehicle-treated control and CUS mice were also found on days 4 and I2, when the NGF effect faded off (a). In the days following the three NGF injections, the difference in pain response between control and CUS mice was no longer detectable (on days I, 7, and 24; a). Drug administration generally induced no significant effects in control mice as compared with vehicle-treated controls (b, $d$, and f), except for a decrease in pain threshold at the pre-NGF time point (day 0 ) of combotreated animals (f). In URB597-treated CUS mice, a statistically significant increase in pain threshold compared with vehicle-treated CUS mice was found on days I, 7, and 24, when the NGF-induced hyperalgesia is elevated (c). JZLI 84 and combo administration did not induce any substantial relief in pain in CUS mice compared with vehicle-treated CUS animals (e and g). Data are expressed as stimulus intensity in gram (g) that elicited the response to determine paw withdrawal threshold. Arrows refer to the days of NGF administrations. Statistical differences between groups are shown at the indicated time points. ${ }^{*} p<0.05,{ }^{*} p<0.01$, *** $p<0.00$ I, Bonferroni's multiple comparison tests after significant two-way ANOVA; $n=8-10$ animals in each group. Additional statistical analyses are reported in Table 3. 
Table 3 Statistical Data Analyses (referred to in Figure 3 and Supplementary Figure I)

\section{Three-way repeated ANOVA}

\begin{tabular}{ll}
\hline Effect & Significance \\
\hline Day & $F_{(6,476)}=13.629, p<0.001$ \\
Treatment & $F_{(3,476)}=10.717, p<0.00 \mid$ \\
Treatment $\times$ stress & $F_{(3,476)}=11.895, p<0.00 \mid$ \\
Stress $\times$ day & $F_{(6,476)}=4.874, p<0.00 \mid$ \\
\hline
\end{tabular}

Two-way ANOVA

\begin{tabular}{lcl}
\hline Day & Effect & Significance \\
\hline 0 & Stress & $\mathrm{F}_{(1,68)}=4.552, p<0.05$ \\
& Treatment $\times$ stress & $\mathrm{F}_{(3,68)}=3.326, p<0.05$ \\
& Stress & $\mathrm{F}_{(1,68)}=4.049, p<0.05$ \\
& Treatment & $\mathrm{F}_{(3,68)}=2.865, p<0.05$ \\
4 & Treatment $\times$ stress & $\mathrm{F}_{(3,68)}=2.368, p=0.07$ \\
& Stress & $\mathrm{F}_{(1,68)}=5.736, p=0.01$ \\
& Treatment & $\mathrm{F}_{(3,68)}=2.716, p=0.05$ \\
& Treatment $\times$ stress & $\mathrm{F}_{(3,68)}=2.668, p=0.05$ \\
& Stress & $\mathrm{F}_{(1,68)}=13.325, p=0.001$ \\
21 & Treatment & $\mathrm{F}_{(3,68)}=5.823, p=0.001$ \\
24 & $\mathrm{~F}_{(3,68)}=3.307, p<0.05$ \\
& Treatment $\times$ stress & $\mathrm{F}_{(3,68)}=2.359, p=0.07$ \\
& Treatment & $\mathrm{F}_{(1,68)}=7.856, p<0.01$ \\
& Stress & $\mathrm{F}_{(3,68)}=4.177, p<0.01$ \\
& Treatment & $\mathrm{F}_{(3,68)}=2.552, p=0.06$ \\
\hline
\end{tabular}

Three-way and two-way ANOVA of results shown in Figure 3 and Supplementary Figure I. For the three-way ANOVA, the effects of 'day', 'treatment', and 'stress' ( $F$ and $p$ values) are shown, and 'day' is the repeated factor. For the two-way ANOVA, 'day' refers to the time points when the Von Frey's filaments test was carried out. The effects of 'stress', 'treatment', and the 'treatment $x$ stress' interaction at each time point ( $F$ and $p$ values) are shown, for simplicity, only when a statistical significance or a tendency to significance was found. Results were further analyzed by Bonferroni's post-hoc test to identify differences between group means. Statistical results from post-hoc analysis are shown as asterisks at the indicated time points in Figure 3 and Supplementary Figure I.

\section{Determination of Endocannabinoid Levels}

The effects of CUS and drug treatments on AEA, 2-AG, and PEA levels were investigated in different brain regions, serum, and left NGF-injected GS muscle by using LC-MRM (Figures 4 and 5 and Supplementary Figure 2; two-way ANOVA in Table 4 and Supplementary Table 1). Consistent with previous reports (Bortolato et al, 2007), CUS did not affect the basal level of AEA (Figure 4), 2-AG (Figure 5), and PEA (Supplementary Figure 2) in any of the tissues examined. Nevertheless, in the serum of vehicle-treated CUS mice a decrease in AEA (Figure 4g) and PEA (Supplementary Figure $2 \mathrm{~g}$ ) was observed as compared with controls, although it was not statistically significant $(p=0.2)$. In vehicle-treated control and CUS mice, the basal AEA levels were similar among the brain regions except for the hypothalamus (Figure 4d), where the AEA content was about two- to threefold lower compared with the other regions. Interestingly, in the GS muscle, the basal levels of AEA (Figure 4h), 2-AG (Figure 5h), and PEA (Supplementary Figure 2h) were about 5- to 10-fold lower compared with the brain. URB597 treatment increased AEA level by about a twofold in most brain regions (Figure 4a-d) and in GS muscle (Figure $4 \mathrm{~h}$ ) of both control and CUS mice but was not significant in hippocampus and less pronounced in prefrontal cortex, as reported before (Bortolato et al, 2007). In midbrain (Figure 4e) and spinal cord (Figure 4f), URB597 increased AEA level by about a sixfold, indicating that pharmacological inhibition of FAAH increases AEA level to different extents in tissues. The reduced increase of AEA levels by URB597 in brain regions involved in the modulation of emotional states (hippocampus and prefrontal cortex) is surprising. However, prolonged exposure to the drug has been proposed to lead to a 'downregulation of AEA mobilization' in certain brain tissues (ie, hippocampus) by mechanisms that remain yet largely unknown (Bortolato et al, 2007). Interestingly, in CUS mice, URB597 induced a statistically significant increase in AEA and PEA serum levels (Figure $4 \mathrm{~g}$ and Supplementary Figure $2 \mathrm{~g}$ ) as compared with vehicle-treated CUS animals, indicating that the drug was able to reverse the apparent basal decrease of AEA and PEA observed in CUS mice as compared with controls. No difference between vehicle- and JZL184-treated mice in AEA or PEA levels was found (data not shown). Combo treatment produced a higher increase in AEA compared with URB597 in the midbrain (Figure 4e) and GS muscle (Figure 4h) of control mice only and in the cingulate cortex (Figure 4b) of both control and CUS mice. This suggests that simultaneous inhibition of FAAH and MAGL produces a synergistic increase in AEA and PEA levels in a tissuespecific manner. No change in the basal level of 2-AG was found in CUS mice compared with controls, although a decrease was found in the hippocampus (Figure 5c), as reported by Hill et al (2005), which, however, in our case, was not statistically significant $(p=0.2)$. The basal $2-\mathrm{AG}$ levels differed among the brain regions; the highest amounts were found in the hypothalamus (Figure 5d), midbrain (Figure 5e), and spinal cord (Figure 5f). URB597 treatment did not affect 2-AG levels in mice (data not shown), whereas JZL184 administration promoted a strong increase in 2-AG levels which, intriguingly, occurred more in control than CUS mice in the cingulate cortex (Figure $5 \mathrm{~b}$ ), spinal cord (Figure 5f), and serum (Figure 5g). Combo treatment induced a synergistic increase in 2-AG levels as compared with JZL184 in the prefrontal and cingulate cortex (Figure 5a and b), hippocampus (Figure 5c), hypothalamus (Figure 5d), and GS muscle (Figure 5h) in control mice but, surprisingly, not in CUS mice.

\section{DISCUSSION}

Neuropsychiatric disorders represent a leading cause to develop chronic widespread pain (Bailey et al, 2010; Denk et al, 2014). Patients with depression for instance, often complain about chronic pain (predominantly in the musculoskeletal system and lower back), which in some cases is treatable with antidepressant drugs (Jann and Slade, 2007). This evidences a close interaction between psychophysiological 


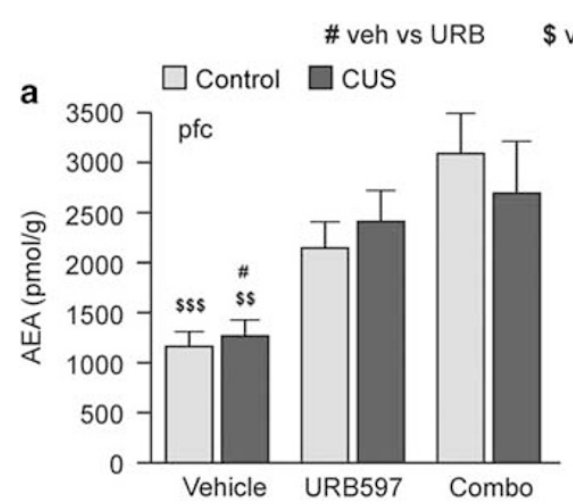

\$ veh vs combo U URB vs combo
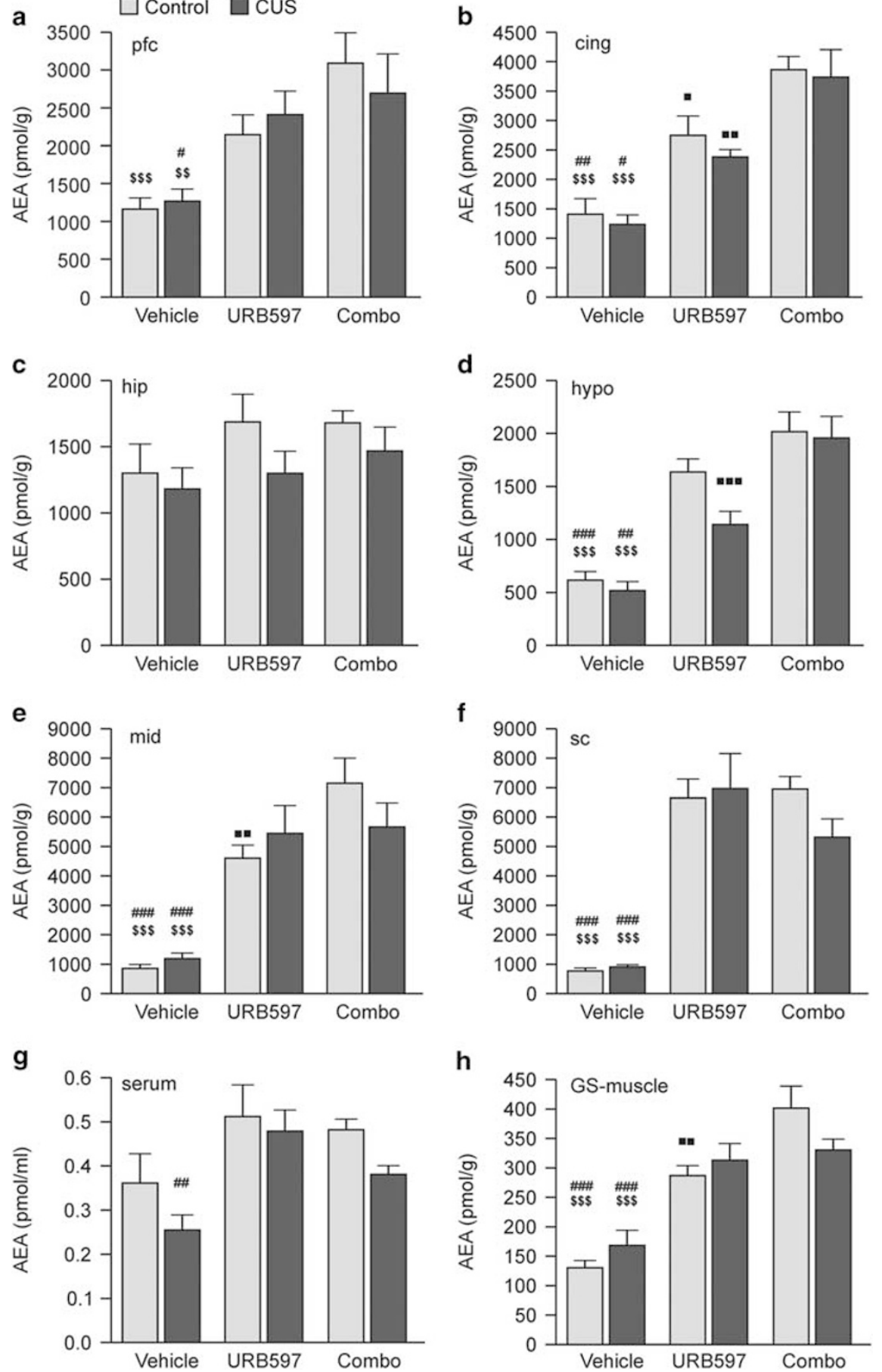

Figure 4 Quantification of anandamide (AEA) in brain, muscle, and serum by LC-MRM. CUS did not change AEA levels in brain (a-f) and left GS muscle $(h)$, as no difference between vehicle-treated control and CUS mice was found. A non-statistically significant decrease $(p=0.2)$ in AEA level in vehicletreated CUS mice compared with controls was observed only in serum (g). URB597 treatment induced a 2-fold increase in AEA level in cingulate cortex (b), hypothalamus (d) and muscle (h) and a 6-fold increase in midbrain (e) and spinal cord ( $\mathrm{f}$ ) and no effect in hippocampus (c) of both animal groups. URB597 also induced a 2-fold increase in AEA level in prefrontal cortex (a) and serum (g) but only in CUS mice. Combo treatment induced a statistically significant increase in AEA level compared with vehicle-treated animals in all tissues except hippocampus (c) and serum (g). Compared with URB597-treated mice, combo treatment induced a synergistic increase in AEA level in midbrain (e) and muscle ( $h$ ) of control mice only and in cingulate cortex (b) of both

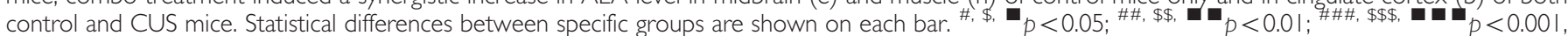
Bonferroni's multiple comparison tests after significant two-way ANOVA; $n=8-10$ animals in each group. Additional statistical analyses are reported in Table 4. AEA, anandamide; cing, cingulate cortex; hip, hippocampus; hypo, hypothalamus; GS-muscle, gastrocnemius-soleus muscle; mid, midbrain; pfc, prefrontal cortex; sc, spinal cord. 


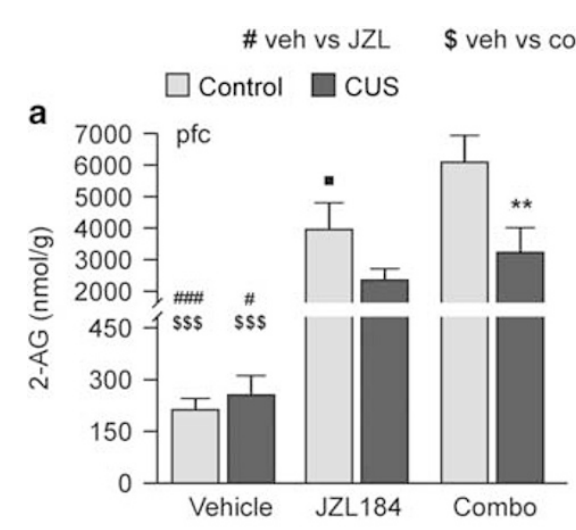

a JZL vs combo * CTR vs CUS
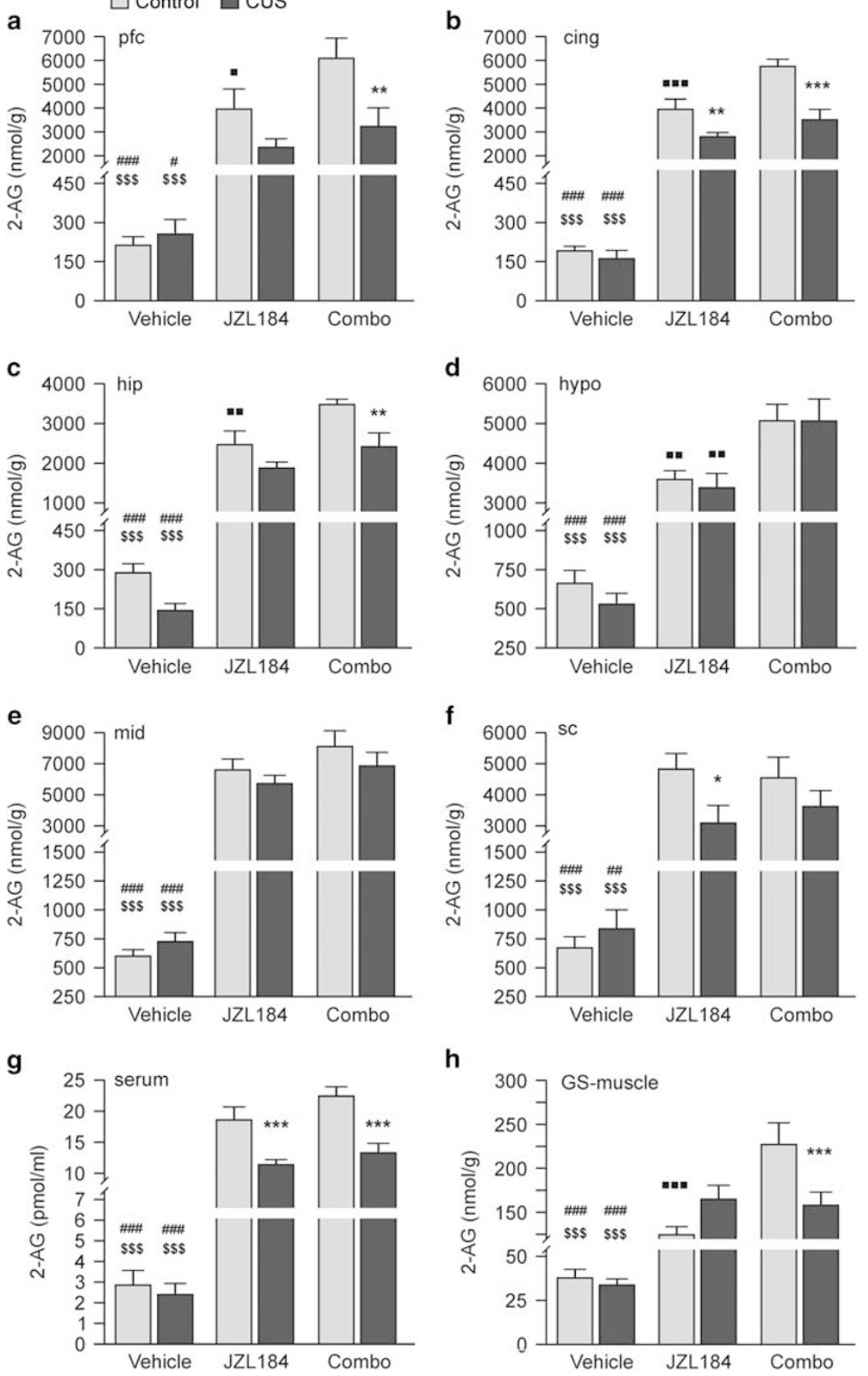

Figure 5 Quantification of 2-arachidonoylglycerol (2-AG) in brain, muscle, and serum by LC-MRM. CUS did not change 2-AG levels in brain (a-f), serum $(\mathrm{g})$, and left GS muscle $(\mathrm{h})$, although a non-statistically significant decrease $(p=0.2)$ of 2-AG in vehicle-treated CUS mice compared with controls was observed only in hippocampus (c). JZLI 84 treatment induced a 3-fold increase in 2-AG levels in all brain regions examined (a-f) of both animal groups. A statistically significant difference between JZL I84-treated control and CUS mice was found in cingulate cortex (b), spinal cord ( $\mathrm{f}$, and serum (g), indicating that the effects of IZLI 84 were stronger in control than in CUS mice. Combo treatment induced a statistically significant increase in 2-AG level compared with vehicle-treated animals in all tissues examined $(a-h)$. Compared with JZLI84-treated mice, combo treatment induced a synergistic increase in 2-AG level only in control mice in almost all tissues ( $a-d$ and h) except midbrain (e), spinal cord ( $\mathrm{f}$, and serum (g). In CUS mice combo-induced synergism

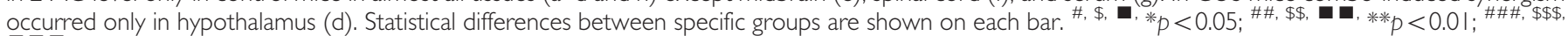
-1. ***** $p<0.001$, Bonferroni's multiple comparison tests after significant two-way ANOVA; $n=8-10$ animals in each group. Additional statistical analyses are reported in Table 4. 2-AG, 2-arachidonoylglycerol; cing, cingulate cortex; hip, hippocampus; hypo, hypothalamus; GS-muscle, gastrocnemius-soleus muscle; mid, midbrain; pfc, prefrontal cortex; sc, spinal cord. 
Table 4 Statistical Data Analyses (referred to in Figures 4 and 5)

Two-way ANOVA

\begin{tabular}{|c|c|c|}
\hline Test & Effect & Significance \\
\hline AEA pfc & Treatment & $F_{(3,57)}=|3.597, p<0.00|$ \\
\hline AEA cing & Treatment & $F_{(3,68)}=32.998, p<0.001$ \\
\hline AEA hip & Treatment & $F_{(3,52)}=9.130, p<0.001$ \\
\hline \multirow[t]{2}{*}{ AEA hypo } & Stress & $F_{(1,68)}=3.517, p=0.06$ \\
\hline & Treatment & $F_{(3,68)}=64.369, p<0.001$ \\
\hline AEA mid & Treatment & $F_{(3,67)}=42.030, p<0.00 \mathrm{I}$ \\
\hline AEA sc & Treatment & $F_{(3,67)}=77.3|4, p<0.00|$ \\
\hline \multirow[t]{2}{*}{ AEA serum } & Stress & $F_{(1,68)}=6.077, p=0.01$ \\
\hline & Treatment & $F_{(3,68)}=7.009, p<0.001$ \\
\hline \multirow[t]{2}{*}{ AEA GS-muscle } & Treatment & $F_{(3,68)}=37.7 \mid 5, p<0.001$ \\
\hline & Treatment $\times$ stress & $F_{(3,68)}=2.557, p=0.06$ \\
\hline \multirow[t]{3}{*}{ 2-AG pfc } & Stress & $F_{(1,67)}=8.274, p<0.01$ \\
\hline & Treatment & $F_{(3,67)}=33.078, p<0.001$ \\
\hline & Treatment $\times$ stress & $F_{(3,67)}=3.381, p<0.05$ \\
\hline \multirow[t]{3}{*}{ 2-AG cing } & Stress & $F_{(1,68)}=20.27 I, p<0.001$ \\
\hline & Treatment & $F_{(3,68)}=|33.159, p<0.00|$ \\
\hline & Treatment $\times$ stress & $F_{(3,68)}=8.077, p<0.001$ \\
\hline \multirow[t]{3}{*}{ 2-AG hip } & Stress & $F_{(1,52)}=9.667, p<0.01$ \\
\hline & Treatment & $F_{(3,52)}=88.184, p<0.001$ \\
\hline & Treatment $\times$ stress & $F_{(3,52)}=2.709, p=0.05$ \\
\hline 2-AG hypo & Treatment & $F_{(3,68)}=99.629, p<0.001$ \\
\hline 2-AG mid & Treatment & $F_{(3,68)}=67.310, p<0.001$ \\
\hline \multirow[t]{3}{*}{$2-A G s c$} & Stress & $F_{(1,67)}=3.518, p=0.06$ \\
\hline & Treatment & $F_{(3,67)}=37.807, p<0.001$ \\
\hline & Treatment $\times$ stress & $F_{(3,67)}=2.464, p=0.07$ \\
\hline \multirow[t]{3}{*}{ 2-AG serum } & Stress & $F_{(1,68)}=\mid 8.357, p<0.001$ \\
\hline & Treatment & $F_{(3,68)}=70.877, p<0.001$ \\
\hline & Treatment $\times$ stress & $F_{(3,68)}=7.045, p<0.001$ \\
\hline \multirow[t]{2}{*}{ 2-AG GS-muscle } & Treatment & $F_{(3,68)}=73.917, p<0.001$ \\
\hline & Treatment $\times$ stress & $F_{(3,68)}=6.429, p=0.001$ \\
\hline
\end{tabular}

Abbreviations: AEA, anandamide; 2-AG, 2-arachidonoylglycerol; cing, cingulate cortex; GS-muscle, gastrocnemius-soleus muscle; hip, hippocampus; hypo, hypothalamus; mid, midbrain; pfc, prefrontal cortex; sc, spinal cord.

Two-way ANOVA of results shown in Figures 4 and 5. The effects of 'stress', 'treatment', and the 'treatment $\times$ stress' interaction for each test ( $F$ and $p$ values) are reported, for simplicity, only when a statistical significance or a tendency to significance was found. Results were further analyzed by Bonferroni's post-hoc test to identify differences between group means. Statistical results from post-hoc analysis are shown as asterisks in Figures 4 and 5.

factors and the neurobiological pain-modulating system, which may initiate a central sensitization to nociceptive stimuli (Sharif-Naeini and Basbaum, 2011; Saab, 2012), ultimately leading to the occurrence of pain.

The ECS has important roles in both psychiatric disorders (Lutz, 2009; Hill and Patel, 2013) and pain states (Kinsey et al, 2009, 2010; Piomelli et al, 2006; Piomelli and Sasso, 2014). The anxiolytic and analgesic properties of inhibitors of FAAH and MAGL have been extensively described (Kathuria et al, 2003; Jhaveri et al, 2006; Rossi et al, 2010;
Sciolino et al, 2011; Ghosh et al, 2013; Hill et al, 2013; Kinsey et al, 2013). Therefore, targeting the ECS may represent a therapeutic strategy, particularly for the treatment of chronic pain associated with emotional imbalance. Persistent stress mediates remarkable physiological changes in the brain (Wang et al, 2010; Hill and Patel, 2013; Denk et al, 2014). Indeed, we found that mice exposed to CUS showed anxiety- and depression-like behavior and also enhanced thermal and mechanical hyperalgesia, which might be due to sustained alterations in the ECS. Previous studies showed that CUS can mediate both analgesic and pro-algesic behavior according to the type of pain measured (Shi et al, 2010). We found that CUS induced mostly hyperalgesia in mice. The effects of stress on eCB levels also vary according to several factors, eg, acute versus chronic and homotypic versus heterotypic stress. An 'AEA-deficient state' has been proposed to occur in rodents exposed to acute or chronic homotypic stress, where a decrease in AEA brain level usually takes place (Hill and Patel, 2013). On the other hand, exposure to chronic heterotypic stress (CUS) produces more variable results (ie, no change in eCB levels), likely due to triggering of adaptive mechanisms (Hill and Patel, 2013). Indeed, consistent with Bortolato et al (2007), we found no substantial alterations in $\mathrm{eCB}$ contents in brain and GS muscle of CUS mice versus controls. Although we did not detect an 'AEA-deficient state' in CUS mice, URB597 exerted anxiolytic and analgesic effects (discussed later), suggesting that in mice exposed to chronic heterotypic stress (CUS) enhancement of the 'AEA state' is beneficial. The extensive analysis of eCB levels carried out in this study provided additional valuable information, as we found that the basal levels of AEA and 2-AG are about 5- to 10-fold lower in the GS muscle as compared with the brain.

Intriguingly, we found that URB597 reversed the decrease of AEA and PEA in the serum of CUS mice, but not in controls (Figure 4 and Supplementary Figure 2), suggesting that the stress-induced effects in CUS mice may involve both AEA and PEA. URB597 also led to a higher increase of AEA in spinal cord and midbrain as compared with the other tissues, suggesting that the enzyme may be more abundant and/or that URB597 is more effective in inhibiting FAAH in these regions. Spinal cord and midbrain, containing the periaqueductal gray, are important regions involved in the modulation of pain processing. In CUS mice, еСB signaling enhancing drugs induced remarkable effects. Indeed, URB597 administration was effective in decreasing the mechanical hyperalgesia and the anxiety-like behavior induced by CUS in mice even in more challenging anxiety tests (EPM), whereas JZL184, consistent with previous reports (Sciolino et al, 2011; Sumislawski et al, 2011), was not. Interestingly, simultaneous inhibition of FAAH and MAGL (combo), known to induce analgesia in mice (Long et al, 2009b), did not elicit further alleviation of the CUSinduced anxiety and hyperalgesia as compared with individual drug administration. Notably, in our experiments, neither URB597, JZL184, nor combo treatment reversed the depression-like behavior observed in CUS mice. Although the anti-depressant properties of URB597 (Bortolato et al, 2007) and JZL184 (Zhong et al, 2014) in stress-exposed rodents have been reported, several factors (animal species, type of behavioral test, duration and type of stressors, design of treatment, dose of drugs) may explain the 
discrepancy between our data and previous studies. Further investigations should shed light on these differences in efficacy of treatments. A rather unexpected finding was the anxiogenic and depression-like effects observed in control mice (ie, not exposed to CUS), which received JZL184 or combo treatment (Figure 2). These JZL184-induced behaviors did not occur in CUS mice and were not induced by URB597. This suggests that an increase in 2-AG rather than AEA levels is responsible for these behaviors and indicates differential roles of these two eCBs in brain functions (Gorzalka et al, 2008; Pan et al, 2009). The anxiogenic and depression-like effects observed in the control mice cannot be related to the dosage of JZL184, as the dose used here $(8 \mathrm{mg} / \mathrm{kg} /$ day $)$ did not induce cannabimimetic effects, in agreement with previous works (Long et al, 2009a; Schlosburg et al, 2010; Wise et al, 2012). The moderate dose employed here should also be devoid of the decreased $\mathrm{CB} 1$ receptor function observed at high doses of the drug (Schlosburg et al, 2010; Kinsey et al, 2013), although, differently from these previous reports, in our case the duration of the treatment was longer. As JZL184-induced increase in 2-AG levels is dependent on the dose as well as the duration of the treatment (Kinsey et al, 2013), one possibility is that in healthy mice (controls) chronic administration of JZL184 may have exacerbated the 2-AG-signaling, along with an eventual loss of MAGL activity-dependent neuroprotective mechanisms (Nomura et al, 2011), to an extent sufficient to produce the behavioral responses observed, and which usually occur at high doses of CB1 receptor agonists (Rey et al, 2012). Indeed, JZL184 and combo treatments induced a statistically significant higher increase in 2-AG level in controls as compared with CUS animals (Figure 5). In control mice, we also found a synergistic increase in 2-AG level induced by combo treatment as compared with JZL184, suggesting that simultaneous inhibition of FAAH and MAGL induced cross-talk between eCB signaling in healthy animals. On the contrary, CUS mice showed reduced increase in 2-AG by JZL184, no combo-induced synergism, and consequently, no drug-induced anxiogenic and depression-like effects as seen in controls. This leads to the speculation that the druginduced exacerbation/over-activation of the 2-AG signaling, supposedly occurring in the control mice, does not happen in the CUS mice, because their 2-AG signaling is already perturbated by chronic stress exposure (Gorzalka et al, 2008; Dubreucq et al, 2012). Further investigations must be pursued to elucidate the mechanisms underlying these drug-induced effects.

Importantly, this study demonstrates that $\mathrm{eCB}$ degradation inhibitors reduce the CUS-induced thermal hyperalgesia in the hot plate test, which measures a centrally mediated pain (Raquibul Hasan et al, 2010). In contrast, mechanical hyperalgesia (Von Frey's filaments test) was reversed only when CUS was co-applied with NGF and only by URB597 administration. Here, co-application of CUS and NGF was essential to establish a model where psychophysiological impairments coexist with long-lasting nociception. Repeated intramuscular NGF injections activate nociceptive muscle afferent fibers, which lead to a longlasting central sensitization to nociceptive stimulations (Hoheisel et al, 2007, 2013). Remarkably, we found that repeated NGF administrations produced not only a localized hyperalgesia restricted to the injection side, but also evoked decreased pain thresholds at the contralateral control side, indicating that the animals developed a longlasting widespread hyperalgesia. This spread of hyperalgesia may be due to activation of nociceptive processes at spinal level, where the complex NGF/tyrosine kinase receptor-A is known to be trafficked and to facilitate the expression of pain-modulating proteins, which may finally lead to a contralateral sensitization. Events of spread hyperalgesia have been reported in other animal models of chronic muscle pain (Sluka et al, 2001; Chang et al, 2010).

The NGF-induced hyperalgesia was not as pronounced in CUS mice as in controls probably because it was obscured by the already reduced pain threshold induced by CUS in these mice. On the other hand, in CUS mice, nociception persisted also after the NGF effect faded off, suggesting that CUS mediated a sustained hyperalgesia in these mice (Figure 3a). NGF and eCB signaling are known to influence each other (Farquhar-Smith and Rice, 2003; Cantarella et al, 2011; Keimpema et al, 2013; Luongo et al, 2014). Intensification of pain by co-administration of NGF with additional insults (ie, acidic solutions) has also been reported (Deising et al, 2012). Our data suggest that in the CUS/NGF mouse model distinct mechanisms are triggered and appear to be modulated by the ECS, as revealed by the ability of URB597 to reverse pain only when CUS and NGF are co-applied (Figure 3c). Finally, we found that a pharmacological increase of 2-AG levels did not alleviate nociception in the CUS/NGF model, as JZL184 and combo treatments were ineffective. In conclusion, our findings demonstrate that the CUS/NGF mouse model is a valid approach to investigate chronic widespread pain associated with emotional disturbance and that this specific type of pain is likely modulated by the ECS. Particularly, pharmacological blockade of FAAH by URB597 was the most effective option to reverse NGF-induced long-lasting hyperalgesia in CUS mice. This suggests that AEA and/or eCB-related lipids (ie, PEA) rather than 2-AG signaling modulate this type of pain. From a clinical perspective, URB597 may represent a promising therapeutic strategy for the alleviation of chronic pain states that frequently occur in patients suffering from concomitant neuropsychiatric disorders.

\section{FUNDING AND DISCLOSURE}

This study was supported by funding from BMBF (LOGIN Project to B.L and U.H.) and from the DFG (FOR926 to B.L.). The authors declare no conflict of interest.

\section{ACKNOWLEDGEMENTS}

We thank Michael Plenikowski for graphic arrangement of the figures and Dr Konstantin Radyushkin for helpful discussions.

\section{REFERENCES}

Bailey KM, Carleton RN, Vlaeyen JW, Asmundson GJ (2010). Treatments addressing pain-related fear and anxiety in patients with chronic musculoskeletal pain: a preliminary review. $\operatorname{Cog} n$ Behav Ther 39: 46-63. 
Bortolato M, Mangieri RA, Fu J, Kim JH, Arguello O, Duranti A et al (2007). Antidepressant-like activity of the fatty acid amide hydrolase inhibitor URB597 in a rat model of chronic mild stress. Biol Psychiatry 62: 1103-1110.

Cantarella G, Scollo M, Lempereur L, Saccani-Jotti G, Basile F, Bernardini R (2011). Endocannabinoids inhibit release of nerve growth factor by inflammation-activated mast cells. Biochem Pharmacol 82: 380-388.

Cattaneo A (2010). Tanezumab, a recombinant humanized mAb against nerve growth factor for the treatment of acute and chronic pain. Curr Opin Mol Ther 12: 94-106.

Chang YW, Tan A, Saab C, Waxman S (2010). Unilateral focal burn injury is followed by long-lasting bilateral allodynia and neuronal hyperexcitability in spinal cord dorsal horn. J Pain 11: 119-130.

Chaplan SR, Bach FW, Pogrel JW, Chung JM, Yaksh TL (1994). Quantitative assessment of tactile allodynia in the rat paw. J Neurosci Methods 53: 55-63.

Deising S, Weinkauf B, Blunk J, Obreja O, Schmelz M, Rukwied R (2012). NGF-evoked sensitization of muscle fascia nociceptors in humans. Pain 153: 1673-1679.

Denk F, McMahon SB, Tracey I (2014). Pain vulnerability: a neurobiological perspective. Nat Neurosci 17: 192-200.

Dubreucq S, Matias I, Cardinal P, Häring M, Lutz B, Marsicano G et al (2012). Genetic dissection of the role of cannabinoid type-1 receptors in the emotional consequences of repeated social stress in mice. Neuropsychopharmacology 37: 1885-1900.

Farquhar-Smith WP, Rice AS (2003). A novel neuroimmune mechanism in cannabinoid-mediated attenuation of nerve growth factor-induced hyperalgesia. Anesthesiology 99: 1391-1401.

Ghosh S, Wise LE, Chen Y, Gujjar R, Mahadevan A, Cravatt BF et al (2013). The monoacylglycerol lipase inhibitor JZL184 suppresses inflammatory pain in the mouse carrageenan model. Life Sci 92: 498-505.

Gorzalka BB, Hill MN, Hillard CJ (2008). Regulation of endocannabinoid signaling by stress: implications for stress-related affective disorders. Neurosci Biobehav Rev 32: 1152-1160.

Hayashi K, Ozaki N, Kawakita K, Itoh K, Mizumura K, Furukawa K et al (2011). Involvement of NGF in the rat model of persistent muscle pain associated with taut band. J Pain 12: 1059-1068.

Hayashi K, Shiozawa S, Ozaki N, Mizumura K, Graven-Nielsen T (2013). Repeated intramuscular injections of nerve growth factor induced progressive muscle hyperalgesia, facilitated temporal summation, and expanded pain areas. Pain 154: 2344-2352.

Herren-Gerber RK, Nie H, Arendt-Nielsen L, Curatolo M, GravenNielsen T (2011). Local pain and spreading hyperalgesia induced by intramuscular injection of nerve growth factor are not reduced by local anesthesia of the muscle. Clin J Pain 27: 240-247.

Hill MN, Kumar SA, Filipski SB, Iverson M, Stuhr KL, Keith JM et al (2013). Disruption of fatty acid amide hydrolase activity prevents the effects of chronic stress on anxiety and amygdalar microstructure. Mol Psychiatry 18: 1125-1135.

Hill MN, Patel S (2013). Translational evidence for the involvement of the endocannabinoid system in stress-related psychiatric illnesses. Biol Mood Anxiety Disord 3: 19.

Hill MN, Patel S, Carrier EJ, Rademacher DJ, Ormerod BK, Hillard CJ et al (2005). Downregulation of endocannabinoid signaling in the hippocampus following chronic unpredictable stress. Neuropsychopharmacology 30: 508-515.

Hoheisel U, Reuter R, de Freitas MF, Treede RD, Mense S (2013). Injection of nerve growth factor into a low back muscle induces long-lasting latent hypersensitivity in rat dorsal horn neurones. Pain 154: 1953-1960.

Hoheisel U, Unger T, Mense S (2005). Excitatory and modulatory effects of inflammatory cytokines and neurotrophins on mechanosensitive group IV muscle afferents in the rat. Pain 114: $168-176$.
Hoheisel U, Unger T, Mense S (2007). Sensitization of rat dorsal horn neurons by NGF-induced subthreshold potentials and lowfrequency activation. A study employing intracellular recordings in vivo. Brain Res 1169: 34-43.

Häring M, Grieb M, Monory K, Lutz B, Moreira FA (2013). Cannabinoid $\mathrm{CB}_{1}$ receptor in the modulation of stress coping behavior in mice: the role of serotonin and different forebrain neuronal subpopulations. Neuropharmacology 65: 83-89.

Jann MW, Slade JH (2007). Antidepressant agents for the treatment of chronic pain and depression. Pharmacotherapy 27: 1571-1587.

Jhaveri MD, Richardson D, Kendall DA, Barrett DA, Chapman V (2006). Analgesic effects of fatty acid amide hydrolase inhibition in a rat model of neuropathic pain. J Neurosci 26: 13318-13327.

Kathuria S, Gaetani S, Fegley D, Valiño F, Duranti A, Tontini A et al (2003). Modulation of anxiety through blockade of anandamide hydrolysis. Nat Med 9: 76-81.

Keimpema E, Tortoriello G, Alpár A, Capsoni S, Arisi I, Calvigioni $\mathrm{D}$ et al (2013). Nerve growth factor scales endocannabinoid signaling by regulating monoacylglycerol lipase turnover in developing cholinergic neurons. Proc Natl Acad Sci USA 110: 1935-1940.

Kinsey SG, Long JZ, Cravatt BF, Lichtman AH (2010). Fatty acid amide hydrolase and monoacylglycerol lipase inhibitors produce anti-allodynic effects in mice through distinct cannabinoid receptor mechanism. J Pain 11: 1420-1428.

Kinsey SG, Long JZ, O’Neal ST, Abdullah RA, Poklis JL, Boger DL et al (2009). Blockade of endocannabinoid-degrading enzymes attenuates neuropathic pain. J Pharmacol Exp Ther 330: 902-910.

Kinsey SG, Wise LE, Ramesh D, Abdullah R, Selley DE, Cravatt BF et al (2013). Repeated low-dose administration of the monoacylglycerol lipase inhibitor JZL184 retains cannabinoid receptor type 1-mediated antinociceptive and gastroprotective effects. J Pharmacol Exp Ther 345: 492-501.

Long JZ, Li W, Booker L, Burston JJ, Kinsey SG, Schlosburg JE et al (2009a). Selective blockade of 2-arachidonoylglycerol hydrolysis produces cannabinoid behavioral effects. Nat Chem Biol 5: 37-44.

Long JZ, Nomura DK, Vann RE, Walentiny DM, Booker L, Jin X et al (2009b). Dual blockade of FAAH and MAGL identifies behavioral processes regulated by endocannabinoid crosstalk in vivo. Proc Natl Acad Sci USA 106: 20270-20275.

Luongo L, Maione S, Di Marzo V (2014). Endocannabinoids and neuropathic pain: focus on neuron-glia and endocannabinoidneurotrophin interactions. Eur J Neurosci 39: 401-408.

Lutz B (2009). Endocannabinoid signals in the control of emotion. Curr Opin Pharmacol 9: 46-52.

Maione S, Costa B, Di Marzo V (2013). Endocannabinoids: a unique opportunity to develop multitarget analgesics. Pain 154(Suppl 1)): S87-S93.

Mills CD, Nguyen T, Tanga FY, Zhong C, Gauvin DM, Mikusa J et al (2013). Characterisation of nerve growth factor-induced mechanical and hypersensitivity in rats. Eur J Pain 17: 469-479.

Mineur YS, Belzung C, Crusio WE (2006). Effects of unpredictable chronic mild stress on anxiety and depression-like behavior in mice. Behav Brain Res 175: 43-50.

Moreira FA, Kaiser N, Monory K, Lutz B (2008). Reduced anxietylike behaviour induced by genetic and pharmacological inhibition of the endocannabinoid-degrading enzyme fatty acid amide hydrolase (FAAH) is mediated by $\mathrm{CB} 1$ receptors. Neuropharmacology 54: 141-150.

Nomura DK, Morrison BE, Blankman JL, Long JZ, Kinsey SG, Marcondes MC et al (2011). Endocannabinoid hydrolysis generates brain prostaglandins that promote neuroinflammation. Science 334: 809-813.

Pan B, Wang W, Long JZ, Sun D, Hillard CJ, Cravatt BF et al (2009). Blockade of 2-arachidonoylglycerol hydrolysis by selective monoacylglycerol lipase inhibitor 4-nitrophenyl 
4-(dibenzo[d][1,3]dioxol-5-yl(hydroxy)methyl)piperidine-1-carboxylate (JZL184) Enhances retrograde endocannabinoid signaling. J Pharmacol Exp Ther 331: 591-597.

Pfizer (2012): Tanezumab: Arthritis Advisory Committee Briefing Document http://www.fda.gov/downloads/AdvisoryCommittees/ CommitteesMeetingMaterials/Drugs/ArthritisAdvisoryCommittee/ UCM295205.pdf.

Piomelli D, Sasso O (2014). Peripheral gating of pain signals by endogenous lipid mediators. Nat Neurosci 17: 164-174.

Piomelli D, Tarzia G, Duranti A, Tontini A, Mor M, Compton TR et al (2006). Pharmacological profile of the selective FAAH inhibitor KDS-4103 (URB597). CNS Drug Rev 12: 21-38.

Raquibul Hasan SM, Hossain MM, Akter R, Jamila M, Mazumder $\mathrm{MEH}$, Alam MA et al (2010). Analgesic activity of the different fractions of the aerial parts of commelina benghalensis linn. Int $J$ Pharmacol 6: 63-67.

Reich CG, Taylor ME, McCarthy MM (2009). Differential effects of chronic unpredictable stress on hippocampal CB1 receptors in male and female rats. Behav Brain Res 203: 264-269.

Rey AA, Purrio M, Viveros MP, Lutz B (2012). Biphasic effects of cannabinoids in anxiety responses: $\mathrm{CB} 1$ and $\mathrm{GABA}(\mathrm{B})$ receptors in the balance of GABAergic and glutamatergic neurotransmission. Neuropsychopharmacology 37: 2624-2634.

Rossi S, De Chiara V, Musella A, Sacchetti L, Cantarella C, Castelli $\mathrm{M}$ et al (2010). Preservation of striatal cannabinoid CB1 receptor function correlates with the antianxiety effects of fatty acid amide hydrolase inhibition. Mol Pharmacol 78: 260-268.

Saab CY (2012). Pain-related changes in the brain: diagnostic and therapeutic potentials. Trends Neurosci 35: 629-637.

Schlosburg JE, Blankman JL, Long JZ, Nomura DK, Pan B, Kinsey SG et al (2010). Chronic monoacylglycerol lipase blockade causes functional antagonism of the endocannabinoid system. Nat Neurosci 13: 1113-1119.

Sciolino NR, Zhou W, Hohmann AG (2011). Enhancement of endocannabinoid signaling with JZL184, an inhibitor of the 2arachidonoylglycerol hydrolyzing enzyme monoacylglycerol lipase, produces anxiolytic effects under conditions of high environmental aversiveness in rats. Pharmacol Res 64: 226-234.

Sharif-Naeini R, Basbaum AI (2011). Targeting pain where it resides... In the brain. Sci Transl Med 3: 65ps1.

Shi M, Qi WJ, Gao G, Wang JY, Luo F (2010). Increased thermal and mechanical nociceptive thresholds in rats with depressivelike behaviors. Brain Res 1353: 225-233.

Sluka KA, Kalra A, Moore SA (2001). Unilateral intramuscular injections of acidic saline produce a bilateral, long-lasting hyperalgesia. Muscle Nerve 24: 37-46.

Sumislawski JJ, Ramikie TS, Patel S (2011). Reversible gating of endocannabinoid plasticity in the amygdala by chronic stress: a potential role for monoacylglycerol lipase inhibition in the prevention of stress-induced behavioral adaptation. Neuropsychopharmacology 36: 2750-2761.

Wang W, Sun D, Pan B, Roberts CJ, Sun X, Hillard CJ et al (2010). Deficiency in endocannabinoid signaling in the nucleus accumbens induced by chronic unpredictable stress. Neuropsychopharmacology 35: 2249-2261.

Wise LE, Long KA, Abdullah RA, Long JZ, Cravatt BF, Lichtman AH (2012). Dual fatty acid amide hydrolase and monoacylglycerol lipase blockade produces THC-like Morris water maze deficits in mice. ACS Chem Neurosci 3: 369-378.

Zhong P, Wang W, Pan B, Liu X, Zhang Z, Long JZ et al (2014). Monoacylglycerol lipase inhibition blocks chronic stress-induced depressive-like behaviors via activation of mTOR signaling. Neuropsychopharmacology 39: 1763-1776.

Supplementary Information accompanies the paper on the Neuropsychopharmacology website (http://www.nature.com/npp) 